\title{
A Study of Supply Chain Risk Factors of the Large- Scale Apparel Manufacturing Companies - Sri Lanka
}

\author{
P.T. Ranil. S. Sugathadasa, S W. Senadheera and A. Thibbotuwawa
}

\begin{abstract}
Apparel industry plays a vital role in the Sri Lankan economy. Hence, it is crucial for Sri Lankan apparel manufacturers to maintain and improve its apparel market share in the international markets. Supply chain operations can be identified as key operations in apparel manufacturing companies. Since they deal with a vast area of policies and institutions, they can increase the risk of exposure for apparel manufacturers. Risk identification and risk assessment are the most critical steps in the risk management process. Therefore, this study helps the large-scale apparel manufacturers to identify the most critical risks they are exposed to that require immediate action. This research has been aligned under three objectives as identification of supply chain risk factors, ranking the identified risks according to their probability and impact using different risk assessment methodologies, and identification of the most accurate risk ranking among them. 30 supply chain risk factors have been assessed in this study and they have been ranked according to the Risk Matrix Methodology and the Borda Count Methodology. The results of this study can be used in extra large scale apparel manufacturing companies to safeguard their businesses by minimising the risk of exposure in supply chain operations.
\end{abstract}

Keywords: Risk factors, Supply chain, Supply chain management, Supply chain risk management

\section{Introduction}

\subsection{Background}

Any organisation cannot survive in the market individually since the performance of one specific organisation depends on the performance of the whole supply chain (SC). Apparel supply chains are made of widely distributed institutions, policies and processes. Each of them who can influence a particular organisation can be divided into two major types of environments called internal environment and external environment. The organisation can directly influence the policies and institutions within the internal environment whereas the organisation can influence very little on the policies and institutions in the external environment. Risks for the sustainability or the growth of the organisation can arise from any of these environments. They can arise with any business process such as production, planning, marketing, finance or supply chain [1-3].

According to supply chain management literature, the supply chain risk management (SCRM) process can be divided into several steps as mentioned below [2].

1. Analysing the supply chain

2. Identifying the uncertainty sources

3. Identifying the risks
4. Identifying the available prevention strategies

5. Identifying the most suitable strategy by analysing them

6. Implementing the strategy.

After analysing the supply chain, it is critical to identify the sources that can ewoke risks and identify those risks properly to avoid or mitigate them in advance.

\subsection{Apparel Industry Sri Lanka}

After 1970, the apparel and textile industry in Sri Lanka has shown a rapid growth due to the better conditions for the industry such as favourable policies for the export-oriented industries, Board of Investment support, quota

Eng. (Dr.) P.T. Ranil. S. Sugathadasa,

CEng, MIE(SL), B.Sc.Eng(Hons)(Moratuwa), MSc.Eng (Moratuwa), MBA (Colombo), PhD (Moratuwa), PMP,

Senior Lecturer, Department of Transport and Logistics

Management, University of Moratuwa.

Email:ranil.sugathadasa@themotivator.lk

(iD $h$ ttps://orcid.org/0000-0002-2841-8332

Miss. S. W. Senadheera,

B.Sc.(Hons)TLM (Moratuwa)

Undergraduate, Department of Transport $\mathcal{E}$ Logistics

Management, University of Moratuwa.

Email:sisinisenadheera@gmail.com

(D) $h$ ttps://orcid.org/0000-0002-9552-6077

Dr. A. Thibbotuwawa

B.Sc.(Hons)(Moratuwa), MSc.Eng (IMT-France), PhD.Eng (AAU-Denmark), MIEEE, Senior Lecturer, Department of

Transport and Logistics Management, University of

Moratuwa

Email:amilat@uom.lk

(iD) https://orcid.org/0000-0002-5443-8839 
system for exporting goods provided by the European countries and the US for developing countries and cheap labour availability.

There were around 1061 apparel manufacturing companies in Sri Lanka by 2001 and 23\% of them were large scale manufacturers who had more than 500 employees [3]. There were 61 extra-large scale companies also among them who accounted for more than $70 \%$ of the market share from the Sri Lankan apparel exports [3]. Since then, the garment industry has grown incredibly in just a few years. Currently, there are around 300 large scale apparel manufacturing companies registered in Sri Lanka [4]. About $90 \%$ of the market is owned by those $5 \%$ large scale apparel manufacturers [4].

According to the above statistics, Sri Lankan economy is highly dependent on the large-scale apparel manufacturers. Therefore, the sustainability and the growth of the industry is very important for the Sri Lankan economy. Same as other countries, Sri Lankan apparel industry has also been exposed to many risks as individual organisations and as an industry. Thus, this study is aimed in identifying and ranking 30 critical SC risks affecting the largescale apparel manufacturing companies in Sri Lanka which will help with providing focus points for risk mitigation plans to reach optimum effectiveness.

\section{Literature Review}

\subsection{Supply Chain}

Different organisations and authors have given different definitions to the supply chain concept. According to the Association for Supply Chain Management (ASCM), the supply chain has been defined in a process basis and a functional basis. As per the process basis definition, according to ASCM, supply chain is the process of linking the suppliers, companies, and users who are engaged in transforming raw materials to ultimate consumption. As per the functional basis definition, a supply chain is the functions inside and outside the company which are engaged in making products or services to the customers [5-7].

The definition of supply chain from the Supply Chain Council also has a functional basis. According to them, the supply chain is a term used to encompass every function, including plan, source, make and deliver, related to the production of a good or service and the delivery of them from the very first supplier to the final consumer. The functional basis concepts for the supply chain which were mentioned above have been used in this study.

\subsection{Company Risk}

Risk is a term that has been defined differently in several business functions such as finance, strategy, marketing, management, and psychology. By considering the different definitions from different business functions, some common features can be discovered concerning risk identification as listed below [12].

- What are the risks or losses that can arise?

- What is the likelihood of each loss or risk occurring?

- What is the impact if the risk or loss arises?

The loss can be both quantitative such as loss of sales and qualitative such as loss of brand image. In addition to the above features from different perspectives, there are some objective definitions as well for risk [8-10]. Risk is the occurrence of any undesired disturbance or outcome other than the expectation $[8,11]$. Risk is influenced by two major factors called likelihood or probability of the loss occurring and the impact or the significance of the mentioned loss if it occurs. So, an equation can be modelled as mentioned below [12].

$$
\begin{aligned}
& \text { Risk }_{n}=\text { Probability }_{n} \times \text { Impact }_{n} \\
& (n=\text { loss })
\end{aligned}
$$

The probability of any risk occurring also depends on the amount of exposure to the risk and the extent of realisation. Some strong businesses can partially or totally influence the risk realisation whereas small scale businesses can only adjust with the risks or the influences from the business environment [5].

The impact of the risks works differently on high growth industries and low growth industries [5]. As an example, the lack of information risk affects similarly on both high growth industries and low growth industries while the risk of inability to reach innovation targets highly affects high growth industries than low growth industries. In general, it is not possible to measure the impact of risks unless the particular organisation has laws and regulations defining the relation. 


\subsection{Supply Chain Risk}

General risk management studies only assess the risk related to an individual company. SCRM is about assessing the risks related to the entire supply chain [13, 14] and the supply chain risks have arisen with globalisation and the inability of the organisations to cope with trends/ firm's consolidation [1]. Highly complex business networks are more likely to face risks related to the supply chain since a greater number of interfaces increases the vulnerability among them $[8,13]$.

The conditions, surroundings and the forces which lay inside the organisational boundaries that affect the assets, functions or performance of the organisation directly or indirectly, are called the organisational internal environment. The institutions and the forces which lay outside the organisational boundaries that affect the assets, functions or performance of the organisation directly or indirectly, are called organisational external environment [4, 9].

Organisational risks can be divided based on the business environment. They are risks from the internal business environment and the external business environment [2].
Supply chain risk can also arise from both of these dynamic environments. Therefore, this study has been conducted considering the organisational environment categorisation and the organisational risk categorisation $[2,4]$.

The internal business environment has been further divided into process risk and control risk to simplify the study [10]. All losses occur due to the malfunctions in the business processes are called process risk [8]. According to the definition from International Standard of Auditing, control risks occur due to the malfunctions and the faults of the systems that are used to control the business which include the supportive activities to the value-added services or the main process. Due to the changing nature of the businesses, there is no solid management solution which will suit all the circumstances of the process or control risks in the long run.

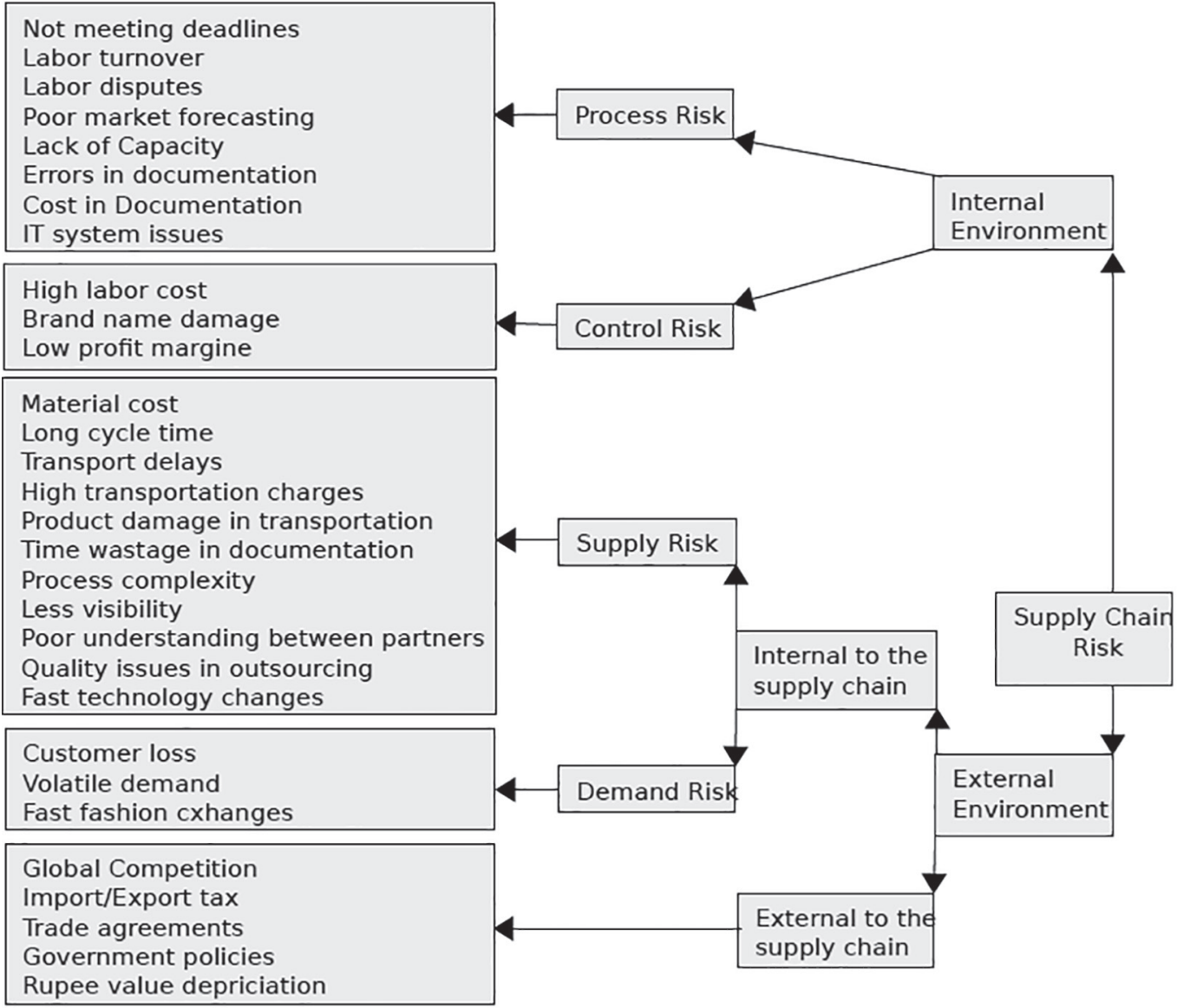

Figure 1 - Conceptual Framework 
All these strategies must be continuously reviewed and updated by the decision-makers [7].

Risks from organisational external environment can be further divided into two as "risks which are internal to the relevant supply chain, but external to the organisation" and "risks which are external to the relevant supply chain and the organisation" [15-17]. Risks which are internal to the relevant supply chain but external to the organisation can be further divided into supply risks and demand risks. All the risks related to functions between raw material processing to the finished goods retailer within the supply chain, are called supply risks. Demand risks can be defined as the reasons for the gap between actual demand within a specific time and the expected demand within that period. Forecasting the market demand has been a difficult task for the apparel industry due to the dynamic nature of the economic environment [15].

\section{Research Methodology}

This study has been built according to the conceptual framework mentioned in Figure 1.

This research has an inductive research approach. It was begun by collecting supply chain risk factors in large scale apparel manufacturing companies and then measuring the severity of each factor according to the experience of field experts. Hence, the results of the study state the supply chain risk factors in a sequence according to the severity of them.

This descriptive research evaluated the current situation of 15 large scale apparel manufacturing companies in Sri Lanka and ranked 30 identified supply chain risks according to their probability of occurrence and the loss or the impact of it, if the risk occurs.

This research was developed to yield both exploratory and conclusive results. Since this research is addressing the risk of exposure of the large-scale apparel manufacturing companies in Sri Lanka and gives insights of it with evidence, this has an exploratory research design approach. This study was conducted using two risk assessment methodologies. The conclusion of this research will help to identify the most suitable risk assessment methodology among these two along with the most accurate risk ranking. Therefore, this research has a conclusive research design approach as well.
This research has a semi-quantitative approach since the qualitative data have been collected in the form of quantitative data and quantitative risk analysis methodologies have been used to analyse them.

\subsection{Population Sampling}

There were around 1045 exporters who exported garment products from Sri Lanka by 2002 according to the custom reports. Around $23 \%$ of them were large scale apparel manufactures. They account for more than $90 \%$ of the garment exports in the country. There are around 300 large scale apparel manufacturing companies operating by 2013 [6]. Even among them more than $70 \%$ of the total garment exports were exported by extra-large scale apparel manufactures. But more than $50 \%$ of those total exports were made by just $4 \%$ key players in the industry [3]. Those key market players were the target population for this research since they largely impact the country's economy. This research was done using a nonprobability sampling method. The key players in the garment exports account for more than $50 \%$ of the export earnings. The purpose of this research was to identify the risk factors in the industry that can have a huge impact on the Sri Lankan economy. By identifying them and taking preventive action in advance, more than $50 \%$ of the export earnings can be saved. The most influencing key players were selected using purposive sampling.

Since it is not easy to identify all the key players in the market due to the unavailability of data and inconceivable to reach or make connections with all the key players, only a few of them were selected using convenient sampling methods. 15 such key players were assessed in this study [6]. Then the respondents within one selected company were also chosen from convenience sampling method because it is difficult to reach and collect data from some eligible respondents.

\subsection{Data Collection}

The data collection was planned according to the requirement of risk assessment methodologies as well. Both primary and secondary data were used for this study. The secondary data were collected using a literature survey to list down the supply chain risk factors affecting large scale apparel manufacturing companies. Both overseas and Sri Lankan studies were assessed to distinguish the factors. 30 risk factors related to the supply 
chain functions in apparel manufacturing firms were identified by referring to available literature. The primary data required for this study were collected from questionnaires in two stages. The eligible population who possessed adequate knowledge and experience about the risk exposure of the companies were executive and above level employees who are well educated and had enough experience in the industry. The accuracy or the applicability of the secondary data in practical context were measured using primary data.

\subsection{Data Analysis}

Most of the risk assessment through literature was conducted by classifying the risk concept into two major categories. Accordingly, any business risk has two phases as probability or the likelihood of the risk occurring and the impact of it on the business or the loss that the business has to bear from the mentioned risk if the risk impacts the business performance. This simplifies and eases the decision making about the risk exposure since the availability of multiple criteria makes it too complex to make decisions whilst reducing the accuracy [9].

\subsection{Risk Matrix Methodology}

This semi-quantitative risk assessment methodology has been used widely in risk analysis research [15]. Risk Matrix methodology has been developed using the probability and the impact as mentioned above. The probability and the impact of the risks can be measured from Likert scales from 1 to 3/ 5/ 7 or 10.1 to 7 Likert scale was devised as mentioned below to rate the probability of occurrence of the mentioned risks [16].

\begin{tabular}{|l|l|}
\hline 1 & Very low probability \\
\hline 4 & $50 \%$ probability of occurring \\
\hline 7 & $100 \%$ probability \\
\hline
\end{tabular}

Likewise, 1 to 7 Likert scale was devised as mentioned below to rate the impact of the mentioned risks.

\begin{tabular}{|l|l|}
\hline 1 & Minor impact \\
\hline 4 & Few moderately negative impacts \\
\hline 7 & Huge business loss \\
\hline
\end{tabular}

After assessing the probability and the impact of the mentioned risks, the overall risk was quantified as per the below mentioned equation.
Risk $=$ Probability of loss $\times$ Impact of the loss

Then the identified risks were ranked according to the multiplicated value by arranging them in a sequence from the highest to the lowest number. The severity of each risk was grouped according to the probability and the impact. As Low as Responsibly Practicable (ALARP) principle was used to identify the high, medium and low risk regions in the risk matrix [18].

\subsection{Borda Count Methodology}

Borda Count methodology gives rankings by comparing each factor in pairs considering each respondent's ranking. Though this methodology has not been used widely in risk assessment research, Borda Count methodology is one of the most suitable among the ranking methods [19]. This gives the priority to the risks that have higher rates from many respondents. Neglecting the majority criterion is a disadvantage of this methodology [19].

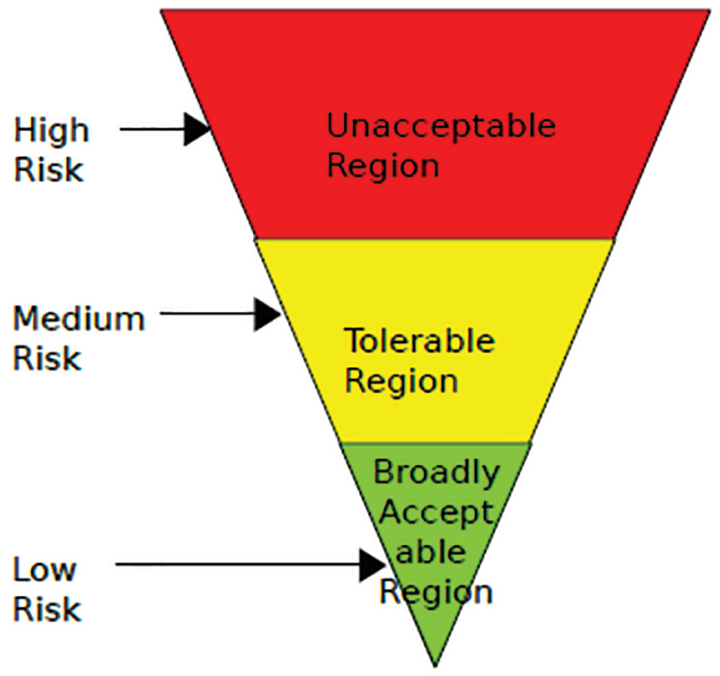

Figure 2 - ALARP Triangle

Table 1 - Matrix Categorisation

\begin{tabular}{|l|l|l|}
\hline $\begin{array}{l}\text { Number of } \\
\text { Cells in } \\
\text { Matrix }\end{array}$ & $\begin{array}{l}\text { Risk } \\
\text { Level }\end{array}$ & Tolerability \\
\hline $2-5$ & Low & Broadly acceptable region \\
\hline $6-8$ & Medium & Tolerable region \\
\hline $9-14$ & High & Unacceptable region \\
\hline
\end{tabular}

\section{Research Findings}

According to the outcome of the first stage survey, the mentioned 30 risk factors had the following statistical features for the questions asked about the probability of occurrence. 
Table 2 - Statistical Representation - Probability and Impact of Risk Factors

\begin{tabular}{|c|c|c|c|c|c|c|c|c|c|c|c|c|}
\hline \multirow{2}{*}{\multicolumn{4}{|c|}{ Risk factor }} & \multicolumn{5}{|c|}{ Probability } & \multicolumn{4}{|c|}{ Impact } \\
\hline & & & & Sum & Mean & Mode & Rank & SD & Sum & Mean & Mode & Rank \\
\hline \multicolumn{4}{|c|}{ A- Not meeting deadlines } & 38 & 3.642 & 4 & 17 & 1.800 & 568 & 5.358 & 7 & 3 \\
\hline \multicolumn{4}{|c|}{ B- Labor turnover } & 45 & 4.302 & 5 & 5 & 1.581 & 552 & 5.208 & 6 & 4 \\
\hline \multicolumn{4}{|c|}{ C- High labor cost } & 45 & 4.245 & 4 & 6 & 1.420 & 529 & 4.991 & 5 & 10 \\
\hline \multicolumn{4}{|c|}{ D- Labor Disputes } & 36 & 3.415 & 4 & 24 & 1.524 & 484 & 4.566 & 5 & 23 \\
\hline \multicolumn{4}{|c|}{ E- Poor market Forecasting } & 36 & 3.443 & 2 & 23 & 1.724 & 529 & 4.991 & 5 & 10 \\
\hline \multicolumn{4}{|c|}{ F- Material Cost } & 44 & 4.189 & 4 & 8 & 1.468 & 543 & 5.123 & 6 & 5 \\
\hline \multicolumn{4}{|c|}{ G- Long cycle time } & 42 & 3.991 & 4 & 11 & 1.509 & 522 & 4.925 & 6 & 14 \\
\hline \multicolumn{4}{|c|}{ H- Lack of capacity } & 37 & 3.491 & 3 & 21 & 1.652 & 484 & 4.566 & 6 & 23 \\
\hline \multicolumn{4}{|c|}{ I- High transport charges } & 26 & 2.519 & 1 & 30 & 1.605 & 492 & 4.642 & 6 & 21 \\
\hline \multicolumn{4}{|c|}{ J- Product damage while transporting } & 38 & 3.594 & 2 & 18 & 1.620 & 472 & 4.453 & 4 & 27 \\
\hline \multicolumn{4}{|c|}{ K- Transport delays } & 36 & 3.481 & 2 & 22 & 1.742 & 527 & 4.972 & 6 & 12 \\
\hline \multicolumn{4}{|c|}{ L- Errors in documents } & 33 & 3.160 & 2 & 28 & 1.697 & 481 & 4.538 & 6 & 26 \\
\hline \multicolumn{4}{|c|}{ M- Time wastage in documentation } & 35 & 3.349 & 2 & 27 & 1.645 & 446 & 4.208 & 4 & 29 \\
\hline \multicolumn{4}{|c|}{ N- Cost (paper, mailing, transportation) } & 37 & 3.547 & 3 & 20 & 1.586 & 440 & 4.151 & 4 & 30 \\
\hline \multicolumn{4}{|c|}{ O- Process complexity } & 41 & 3.877 & 4 & 13 & 1.666 & 484 & 4.566 & 3 & 23 \\
\hline \multicolumn{4}{|c|}{ P- Less visibility in supply chain } & 38 & 3.670 & 4 & 16 & 1.608 & 498 & 4.698 & 5 & 19 \\
\hline \multicolumn{4}{|c|}{ Q- IT system issues } & 35 & 3.368 & 2 & 26 & 1.675 & 453 & 4.274 & 5 & 28 \\
\hline \multicolumn{4}{|c|}{ R- Poor understanding between SC partners } & 35 & 3.377 & 2 & 25 & 1.546 & 487 & 4.594 & 4 & 22 \\
\hline \multicolumn{4}{|c|}{ S- Brand name damages } & 29 & 2.755 & 1 & 29 & 1.871 & 539 & 5.085 & 7 & 6 \\
\hline T-Quality & $\mathrm{sin}$ & ed & & 37 & 3.557 & 3 & 19 & 1.862 & 535 & 5.047 & 7 & 8 \\
\hline U- Impor & ort & & & 41 & 3.868 & 4 & 14 & 1.604 & 509 & 4.802 & 5 & 18 \\
\hline V- Unfav & $\mathrm{e} \mathrm{cl}$ & 110 & ements & 39 & 3.755 & 4 & 15 & 1.700 & 516 & 4.868 & 5 & 16 \\
\hline W- Unfav & le g & 11 & & 44 & 4.160 & 4 & 9 & 1.544 & 532 & 5.019 & 5 & 9 \\
\hline X-Rupee & dep & & & 47 & 4.519 & 6 & 3 & 1.811 & 513 & 4.840 & 6 & 17 \\
\hline Y- Low $p$ & Iarg & , & & 44 & 4.226 & 4 & 7 & 1.703 & 520 & 4.906 & 5 & 15 \\
\hline Z- Techn & har & & & 41 & 3.953 & 4 & 12 & 1.769 & 496 & 4.679 & 5 & 20 \\
\hline AA-Glob & ipet & & & 52 & 4.953 & 6 & 1 & 1.629 & 578 & 5.453 & 6 & 2 \\
\hline AB- Cust & & & & 46 & 4.406 & 6 & 4 & 1.901 & 604 & 5.698 & 7 & 1 \\
\hline AC- Vola & $\mathrm{ma}$ & & & 44 & 4.160 & 4 & 9 & 1.538 & 526 & 4.962 & 6 & 13 \\
\hline AD- Fast & $\mathrm{n} \mathrm{cl}$ & & & 49 & 4.632 & 6 & 2 & 1.742 & 536 & \begin{tabular}{|l|}
5.057 \\
\end{tabular} & 6 & 7 \\
\hline & 7 & & & & $\mathrm{~T}$ & A & & & & $A B$ & & \\
\hline & 6 & 1 & K L & & H & F G A & & B & & AA AD & & \\
\hline & 5 & & $\mathrm{EQ}$ & & & $\begin{array}{r}\text { CDPU } \\
\mathrm{Z}\end{array}$ & V W Y & & & & & \\
\hline Impact & 4 & & $J M R$ & & No & & & & & & & \\
\hline & 3 & & & & & & & & & & & \\
\hline & 2 & & & & & & & & & & & \\
\hline & 1 & & & & & & & & & & & \\
\hline & & 1 & 2 & & 3 & 4 & & 5 & & 6 & & 7 \\
\hline & & & & & & Probab & oility & & & & & \\
\hline
\end{tabular}

Figure 3 - Risk Matrix 


\subsection{Probability of the Risk Factors}

The probability of each risk factor has been assessed separately in Table 2 . If the probabilities were ranked according to the total rank given by every respondent, the most probable five risks are global competition, fast fashion changes, rupee value depreciation, customer loss, and labour turnover. The impact of each risk factor has been assessed separately in Table 2 as well. If the impacts were ranked according to the total rank given by every respondent, the most influencing five risks are customer loss, global competition, inability to meet deadlines, labour turnover and material cost.

\subsection{Risk Matrix}

The risk matrix mentioned in Figure 3 was plotted using the mode of the rankings given by all the respondents for each risk factor. According to the 7 by 7 standard risk matrix, the risks can be categorised into the unacceptable region, tolerable region and broadly acceptable region and visualise as represented in the matrix in Figure 3. As the above statistics represent, there are no broadly acceptable supply chain risks in the identified 30 risk factors. Only 11 risk factors lie under the tolerable region. All the other 19 risk factors need immediate preventive action since they lie under the unacceptable risk region.

Table 3 - Methodology Comparison

\begin{tabular}{|c|c|}
\hline Customer loss & Customer loss \\
\hline Fast fashion changes & Fast fashion changes \\
\hline Labor turnover & Labor turnover \\
\hline Rupee value depreciation & Material Cost \\
\hline Material cost & Volatile Demand \\
\hline High Labor cost & Rupee value depreciation \\
\hline Unfavourable government policies & High Labor cost \\
\hline Low profit margin per product & Unfavourable government policies \\
\hline Volatile Demand & Low profit margin per product \\
\hline Long cycle time & Long cycle time \\
\hline Not meeting deadlines & Customer loss \\
\hline Import/ Export tax & Not meeting deadlines \\
\hline Technology changes & Import/ Export tax \\
\hline Unfavourable changes in trade agreements & Unfavourable changes in trade agreements \\
\hline Quality issues in outsourced services & Process complexity (More parties involved) \\
\hline Process complexity (More parties involved) & Quality issues in outsourced services \\
\hline Transport delays & Poor market Forecasting \\
\hline Less visibility in supply chain & Less visibility in supply chain \\
\hline Poor market Forecasting & Transport delays \\
\hline Product damage while transporting & Product damage while transporting \\
\hline Lack of capacity & Poor understanding between SC partners \\
\hline Labor Disputes & Lack of capacity \\
\hline Poor understanding between SC partners & Labor Disputes \\
\hline Cost (paper, mailing, transportation) & Cost (paper, mailing, transportation) \\
\hline IT system issues & IT system issues \\
\hline Errors in documents & Time wastage in documentation \\
\hline Time wastage in documentation & Errors in documents \\
\hline Brand name damages & Brand name damages \\
\hline High transport charges & High transport charges \\
\hline
\end{tabular}


Table 4 - SC Risk Ranking by Organizational Environment

\begin{tabular}{|c|c|c|c|c|c|}
\hline \multirow{4}{*}{ Rank } & \multicolumn{5}{|c|}{ Organizational Environment } \\
\hline & \multicolumn{2}{|c|}{ Internal Environment } & \multicolumn{3}{|c|}{ External environment } \\
\hline & \multirow{2}{*}{ Process Risk } & \multirow{2}{*}{ Control Risk } & \multicolumn{2}{|c|}{ External to the company } & \multirow{2}{*}{$\begin{array}{l}\text { External to the Supply } \\
\text { Chain }\end{array}$} \\
\hline & & & Demand Risk & Supply Risk & \\
\hline 1 & Labor turnover & High labor cost & Customer loss & Material cost & Global competition \\
\hline 2 & Labor disputes & $\begin{array}{l}\text { Brand name } \\
\text { damages }\end{array}$ & $\begin{array}{l}\text { Fast fashion } \\
\text { changes }\end{array}$ & Long cycle time & $\begin{array}{l}\text { Rupee value } \\
\text { depreciation }\end{array}$ \\
\hline 3 & $\begin{array}{l}\text { Not meeting } \\
\text { deadlines }\end{array}$ & $\begin{array}{l}\text { Low profit } \\
\text { margin per } \\
\text { product }\end{array}$ & $\begin{array}{l}\text { Volatile } \\
\text { Demand }\end{array}$ & Technology changes & $\begin{array}{l}\text { Unfavorable } \\
\text { government policies }\end{array}$ \\
\hline 4 & Lack of capacity & & & $\begin{array}{l}\text { Quality issues in } \\
\text { outsourced services }\end{array}$ & Import/ Export tax \\
\hline 5 & $\begin{array}{l}\text { Poor market } \\
\text { forecasting }\end{array}$ & & & Process complexity & $\begin{array}{l}\text { Unfavorable changes in } \\
\text { trade agreements }\end{array}$ \\
\hline 6 & $\begin{array}{l}\text { Cost in } \\
\text { documentation }\end{array}$ & & & Less visibility & \\
\hline 7 & IT system issues & & & Transport delays & \\
\hline 8 & $\begin{array}{l}\text { Errors in } \\
\text { documentation }\end{array}$ & & & $\begin{array}{l}\text { Product damage } \\
\text { while transportation }\end{array}$ & \\
\hline 9 & & & & $\begin{array}{l}\text { Poor understanding } \\
\text { between SC partners }\end{array}$ & \\
\hline 10 & & & & $\begin{array}{l}\text { Time waste in } \\
\text { documentation }\end{array}$ & \\
\hline 11 & & & & $\begin{array}{l}\text { High transportation } \\
\text { charges }\end{array}$ & \\
\hline
\end{tabular}

\subsection{Borda Count Methodology}

The risk ranking given by this methodology is mentioned in the second column in Table 3.

\subsection{Methodology Comparison}

Comparison of the results received from the aforementioned two methodologies are presented in Table 4. According to the rankings given by Risk Matrix Methodology and Borda Count Methodology, the global competition, customer loss, fast fashion changes and labour turnover can be identified as the most critical four risks. Then the risk matrix methodology identifies the rupee value depreciation as the fifth critical risk while the other methodology presented the material cost in the fifth place.

Both the above rankings gave almost similar rankings with slight changes in some risk ranks. The correlation between two methodologies were deciphered using $R$ statistical language as mentioned in Table 5 to generate correlation matrix. It shows that the correlation coefficient between the outcomes of Risk Matrix Methodology and the Borda Count Methodology is 0.9895467 . Therefore, it can be concluded that both ranking methodologies have a very high correlation. Sum, mean and mode calculated from the rankings given by the field experts (Table 6) indicates that experts prefer the risk ranking given by the Borda Count Methodology over the ranking given by the Risk Matrix Methodology. Hence, the most accurate and suitable risk ranking for large scale apparel manufacturing companies can be ranked as mentioned in the second column in Table 3.

Finally, the risk factors can be aligned by their severity considering the organisational environment which is mentioned in Table 4.

Table 5 - Correlation of the Methodologies

\begin{tabular}{|l|r|r|}
\hline Methodology & \multicolumn{1}{|l|}{ Risk Matrix } & \multicolumn{1}{|c|}{ Borda Count } \\
\hline Risk Matrix & 1 & 0.9895467 \\
\hline Borda Count & 0.9895467 & 1 \\
\hline
\end{tabular}

Table 6 - Statistics

\begin{tabular}{|l|r|r|r|}
\hline Methodology & \multicolumn{1}{|l|}{ Sum } & Mean & Mode \\
\hline Risk Matrix & 161 & 7.666667 & 8 \\
\hline Borda Count & 171 & 8.142857 & 9 \\
\hline
\end{tabular}

\section{Conclusions}

Thirty (30) supply chain risk factors in the apparel manufacturing companies were identified under each organisational environment as not meeting deadlines, labour turnover, high labour cost, labour disputes, poor market forecasting, material cost, long 
cycle time, lack of capacity, high transport charges, product damage while transporting, transport delays, errors in documents, time wastage in documentation, cost of documentation, process complexity, less visibility in supply chain, IT system issues, poor understanding between supply chain partners, brand name damages, quality issues in outsourced services, import/ export tax, unfavourable changes in trade agreements, unfavourable government policies, rupee value depreciation, low profit margin per product, technology changes, global competition, customer loss, volatile demand and fast fashion changes.

Both risk rankings were strongly correlated. But there were slight changes as well. According to both rankings, the four most critical supply chain risk factors were global competition, customer loss, fast fashion changes and labour turnover. A field expertise survey was conducted to identify the most suitable supply chain risk ranking and, according to the feedback of 21 eligible respondents who were in managerial levels with high level of experience in the field, the best risk ranking was the one received from the Borda Count Methodology. According to this study, the most accurate risk rating method is the Borda Count Methodology.

\section{Recommendations}

According to the outcomes of this research, many of the most crucial supply chain risks are from external business environments. The challenges from the external environments are assumed to be difficult to manage. Yet, since large scale apparel manufacturers are big entities in the industry, they can have considerable influence on the external environment as well. Therefore, the companies must exert a higher effort on managing them since it will attract more advantages than the effort put on managing them.

The risks related to employee behaviour were also in the most critical risks. Thus, the companies must focus more on employee satisfaction as well since retaining the employees saves a huge cost for the company. Improving their welfare facilities will be a good way to retain employees. Further, there must be a platform to assess and identify their problems individually to give them solutions, so that those employees can continue to work after overcoming the mentioned problems.
Further, the problems related to supply chain partner integration can be considered a highrisk area as well. A better integration platform must be designed eliminating the communication gaps between them. Furthermore, the complexity of the network must be minimized.

According to the classification of the risk matrix, there is no negligible risk in all the 30 identified supply chain risk factors. Hence, the large-scale apparel manufacturing companies should not take all the mentioned risks lightly. All of them must be taken into consideration and solutions should be generated for each of them.

\section{Implications}

The findings of this study can be applied in future risk assessment studies as well. Since this research states the most critical supply chain risk factors for the large-scale apparel manufactures in Sri Lanka, future researchers can apply them if they need to identify the riskiest supply chain operations for further studies. Since this study shows the ranking of the most probable risks and most impacting risks, they also can be used in relevant studies. The biggest advantage of this study is for the large-scale apparel industry since they can identify the most crucial supply chain risks, most probable risks and most impacting risks by this study. Therefore, the decision-makers in the relevant cluster of companies can identify the risks they need to focus more to manage them. Thus, those companies can avoid and mitigate the impact of them or overcome those challenges to be successful in the industry.

This study identified only the supply chain risks for extra large scale apparel manufacturers in Sri Lanka. Similar studies can be done to identify the risk factors in other operational areas and for small and medium scale apparel manufacturers in Sri Lanka. Since the Borda Count Methodology was identified as the best ranking methodology in this study, it can be used in future studies as well for the risk assessments. Further, such risk ranking studies can be done for the other industries as well. 


\section{References}

1. Hewage, Harsha Chamara, H. Niles Perera, and Shari De Baets. "Forecast Adjustments during Post-Promotional Periods." EJOR, 2021.

2. Sugathadasa, R., Wakkumbura, D., and Perera, H., and Thibbotuwawa, A. "Analysis of Risk Factors for Temperature-Controlled Warehouses", OSCM : Int. J., 14(3), 320-337, 2021.

3. Perera, S., Perera, H.N., and Kasthurirathna, D., "Structural Characteristics of Complex Supply Chain Networks," 2017 Moratuwa Eng. Research Conf. (MERCon), 2017, pp. 135-140, doi: 10.1109/MERCon.2017.7980470.

4. Kodithuwakku, C. E., and Wickramarachchi, D. N., "Identifying the Risk Dynamics of Supply Chain Operations in Large Scale Apparel Industry in Sri Lanka", Int. J. Innov., 6(4), 272277, 2015.

5. Balachandra, K., Perera, H. N., and Thibbotuwawa, A., "Human Factor in Forecasting and Behavioral Inventory Decisions: A System Dynamics Perspective", Int. Conf. Dynamic Logistics. 516-526, Springer, Cham, 2020.

6. Perera, H.N., and Sudusinghe, J.I., "Longitudinal Analysis of Supply Chain Transformation Project Management," 2017 Moratuwa Eng. Research Conf. (MERCon), 2017, pp. 153-158, doi: 10.1109/MERCon.2017.7980473.

7. Perera, H. N., Fahimnia, B., and Tokar, T.," Inventory and Ordering Decisions: A Systematic Review on Research Driven through Behavioral Experiments", Int. J. Opera. E Prod. Manag., 2020.

8. Jayawardhana, S. S., Industry Capability Report-Sri Lankan Apparel Sector, pp. 1- 10, 2016.

9. Sugathadasa, R., De Silva, M. L., Thibbotuwawa, A. and Bandara, K. A. C. P. "Motivation Factors of Engineers in Private Sector Construction Industry". J. App. Eng. Science, pp.1-12, 2021.

10. Markowski, A. S., and Mannan, M. S., "Fuzzy Risk Matrix.", J. Hazard. Materials, 159(1), 152157, 2008.

11. Martino, G., Fera, M., Iannone, R., and Miranda, S., "Supply Chain Risk Assessment in the Fashion Retail Industry: An Analytic Network Process Approach.", Int. J. Appl. Eng. Res, 12(2), 140-154, 2017.
12. Mitchell, V. W., "Organizational Risk Perception and Reduction: A Literature Review.", British J. Manag., 6(2), 115-133, 1995.

13. Pablo, A. L., Eccles, R., Herz, R., Keegan, M., and Phillips, D., "Reconciling Predictions of Decision Making under Risk: Insights from a Reconceptualized Model of Risk Behaviour.", J. Manag. Psy., 14(2), 92108, 1999.

14. Perera, S., Perera, H.N., and Kasthurirathna, D., "Value Chain Approach for Modelling Resilience of Tiered Supply Chain Networks," 2017 Moratuwa Eng. Research Conf. (MERCon), 2017, pp. 159-164, doi: 10.1109/ MERCon.2017. 7980474.

15. Thun, J. H., and Hoenig, D., "An Empirical Analysis of Supply Chain Risk Management in the German Automotive Industry.", Int. J. Prod. Econ., 131(1), 242-249, 2011.

16. Zsidisin, G. A., "A Grounded Definition of Supply Risk.", J. Purch. Supply Manag., 9(5-6), 217-224, 2003.

17. Sugathadasa, P. T. R. S., "Identification and Modelling of Construction Supply Chain Risk Triggers", PhD Diss., 2018.

18. Sugathadasa, R., De Silva, M. L., Thibbotuwawa, A. and Bandara, K. A. C. P., "Motivation Factors of Engineers in Private Sector Construction Industry". J. App. Eng. Science, pp.1-12, 2021.

19. Saari, D. G., "The Optimal Ranking Method is the Borda Count.", Int. Ins. App. Sys. Ana., 155,1985 . 